\section{Os impactos das políticas de austeridade nas condições de saúde dos países com algum tipo de crise}

\author{
Raphael Mendonça Guimarães \\ Fundação Oswaldo Cruz, Escola Politécnica de Saúde \\ Joaquim Venâncio, Rio de Janeiro, RJ, Brasil. \\ $<$ raphael.guimaraes@fiocruz.br>
}

DOI: http://dx.doi.org/10.1590/1981-7746-sol00117

STUCKLER, David.; BASU, Sanjay. A economia desumana: porque mata a austeridade. 1. edição. Editorial Bizâncio: Lisboa, 2014, 302p.

O livro A economia desumana: porque mata a austeridade foi originalmente publicado no ano de 2013 por Stuckler e Basu. Trata dos impactos das políticas de austeridade nas condições de saúde dos países que enfrentaram algum tipo de crise. Foi traduzido para o português em 2014 e, desde então, vem sendo alvo de estudos e resenhas em periódicos das áreas de saúde pública e economia. David Stuckler é pesquisador-sênior da Universidade de Oxford e pesquisador da London School of Hygiene and Tropical Medicine. Já Sanjay Basu é epidemiologista e professor de Medicina na Universidade de Stanford.

Recentemente, o professor Stuckler esteve, em outubro de 2017, no Congresso Brasileiro de Epidemiologia para um lançamento do seu livro e, concomitante ao lançamento, houve a conferência "Efeitos das políticas de austeridade sobre a saúde das populações". Neste momento de crise política no Brasil, em que este tema se torna emergente, parece oportuna a elaboração de uma nova resenha sobre o livro recém-lançado, descrita agora à luz da conjuntura atual.

O ponto de partida dos autores é o que denominam "experimentos naturais", que representam situações em que foram adotadas medidas econômicas por diversos países frente a períodos de crise e instabilidade econômica, e qual a repercussão destas medidas - classificadas como de austeridade ou seguridade - na saúde da população. A proposta do livro é trazer, de forma elucidativa, a evidência gerada pela implementação de políticas públicas e o impacto nos indicadores de saúde.

É importante pontuar que a proposta dos "experimentos naturais" é uma prática recorrente nas ciências sociais aplicadas, uma vez que é difícil, em muitas situações, isolar as causas e os efeitos dos fenômenos de interesse social desta área de conhecimento. Por isso, a ideia de analisar os efeitos (por exemplo, indicadores de morbimortalidade por eventos marcadores, como o caso do suicídio, ou agravos conduzidos por políticas públicas, como o caso da Aids), adotando as práticas econômicas em cenários de crise e recessão como a causa.

A obra de Stuckler e Basu é enfática quando diz que as políticas de austeridade têm efeito devastador sobre a saúde das populações, particularmente não só em indicadores de impacto, como a reemergência de certas doenças, tais como a desnutrição e algumas doenças infecciosas, mas igualmente em indicadores de estrutura e processo, como a razão médico/população e o tempo interconsultas.

Em sua análise, os autores citam que a possibilidade de cortes na execução orçamentária traz um cenário obscuro para um futuro próximo, a exemplo do que ocorreu em alguns países, quando seus governantes optaram por redução de custos como medida de contenção. Enfatiza-se, aqui, que não se trata de cortes de gastos, pois a redução é em cima de elementos de financiamento que são previstos por série histórica, e não sobre valores não previstos - o que caracteriza o corte como um plano de governo, e não como resposta à suposta crise econômica.

Dando historicidade à pesquisa, os autores abordam exemplos que remetem à Grande Depressão de 1929 nos Estados Unidos, e de que forma a austeridade, naquele momento, contribuiu para uma mudança na velocidade da transição epidemiológica naquele país. Adicionalmente, o relato descreve a melhora nos indicadores alavancada, anos depois, graças às medidas geradas pelo New Deal, especialmente na redução da mortalidade infantil. Na sequência, os autores descrevem vários outros experimentos, concentrados em países europeus (ocidentais e orientais), todos eles apontando para a mesma direção: há um impacto negativo quando a decisão econômica é de privatização rápida e não preserva os sistemas de seguridade e bem-estar social.

Stuckler e Basu argumentam, nesta descrição, que há alguns princípios que devem ser considerados nas decisões a respeito da austeridade. Primeiramente, é importante que a diretriz econômica que venha a ser adotada não seja nociva 
à população. Segundo, de alguma forma as ações elaboradas devem ajudar a recuperar, a médio e longo prazo, o acesso a emprego e renda. Finalmente, os autores ponderam que é preciso haver investimentos em saúde pública, em especial nas ações de prevenção de agravos.

Para defender estes aspectos, os autores descrevem exemplos ocorridos nos últimos quarenta anos. Por exemplo, citam a dificuldade mais recente da Grécia em conter epidemias e tratar doentes, quando um investimento em ações preventivas poderia ter minimizado estes efeitos prolongados. Adicionalmente, os autores apontam para um aumento, após declínio sustentado no tempo, na taxa de incidência de HIV, resultado de redução orçamentária em programas de prevenção à Aids.

Outro exemplo trazido é o caso da diferença encontrada entre antigas repúblicas soviéticas, que lidaram com a crise no Leste europeu no início dos anos 1990 de formas distintas. Cita, por exemplo, que os programas de privatização na Rússia e a demolição da era soviética provocaram um aumento na magnitude de morbimortalidade na população. Já em repúblicas com transições mais lentas e sustentadas, como é o caso de Belarus, a saúde pública vivenciou um impacto de menor proporção.

Ainda, na Suécia, foram criados programas de inclusão no mercado de trabalho que, no limite, contribuíram para a redução no número de suicídios, mesmo durante a recessão. Em conclusão, afirmam que “a piora da saúde não é uma consequência inevitável das recessões econômicas. É uma escolha política".

Por fim, é descrito o caso da Islândia, que teve a oportunidade, diante da crise econômica no início do século XXI, de realizar referendos populares para decidir os caminhos futuros da economia. À época, a população votou majoritariamente a favor do pagamento gradativo aos credores internacionais. Houve, ao final, uma recuperação da Islândia, sem que ocorresse um impacto importante, no período, na carga de doenças.

Assim, de forma consistente, os autores descrevem que, em lugar de melhorar o cenário econômico, a austeridade acaba por agravá-lo, além de trazer outros problemas de gestão, como a piora dos indicadores de saúde pública. A conclusão apontada por eles é de que a saúde pública sofrerá mais pela austeridade fiscal do que propriamente pela crise econômica, e nesse sentido é importante garantir políticas públicas adequadas. Ainda, destacam que os efeitos negativos não são inevitáveis, mas dependem organicamente de uma gestão pública forte, que reafirme princípios como a equidade e a justiça social.

Não há consenso, portanto, sobre a origem das crises, e sobre como responder a esta questão. Entretanto, há relativo acordo sobre considerar as medidas de austeridade - como a redução das despesas sociais e o aumento da tributação- um erro (Greer et al., 2017). No que se refere à área da saúde, a implicação se dá no corte de serviços e restrição no acesso aos cuidados (Stuckler et al., 2017). Se considerarmos este tipo de estratégia num sistema de saúde integral e universal, como é o caso brasileiro, as implicações poderão ser severas e ir de encontro à constitucionalidade das medidas adotadas. A partir dos exemplos descritos na obra, pode-se dizer que a conjuntura atual do Brasil tipifica um 'experimento natural', e nesse sentido é importante que se faça uma leitura crítica do cenário atual.

O ano é 2017, e muito se especula, após passado pouco mais de um ano desde o golpe de estado de 2016, o que será do futuro desta 'terra de palmeiras'. A ocasião do lançamento da obra favoreceu a discussão. O congresso, organizado pela Associação Brasileira de Saúde Coletiva (Abrasco) e pela Universidade Federal de Santa Catarina, reuniu pesquisadores de vários lugares do globo, proporcionando um intercâmbio de experiências, muitas delas convergindo para o debate sobre os desafios da saúde pública diante de um cenário de crise, que é o elemento central da obra sobre a qual esta resenha se refere.

A abordagem de Stuckler e Basu, ao longo da obra, reflete a necessidade de orientar as análises epidemiológicas sobre o processo saúde-doença considerando o efeito do contexto, especialmente inserindo a determinação social da saúde. Há que se incorporar o aspecto das iniquidades em saúde, o que torna as análises mais e mais desafiadoras, não só do ponto de vista teórico, mas igualmente do ponto de vista metodológico, exigindo modelos estatísticos explicativos mais robustos.

De forma apropriada, cita-se aqui o desmantelamento de políticas de saúde relativamente consolidadas, como é o caso da Política Nacional de Atenção Básica. Ainda que esta desconstrução não tenha sido contemporânea à redação do livro, ela ocorre concomitante aos debates proferidos por David Stuckler recentemente. Neste momento, há organizações da sociedade civil, bem como associações nacionais e internacionais (como, por exemplo, a Abrasco e a Confederação Iberoamericana de Medicina Familiar - CIMF), emitindo notas a respeito dos riscos da restrição de gastos 
públicos para a estruturação do Sistema Único de Saúde (SUS). É importante destacar, aqui, que não se trata de uma escassez de recurso, mas de priorização. Afirma-se isso diante das manobras realizadas pelo governo para garantir uma suposta 'harmonia de democracia', capitaneando o Brasil com a troca de interesses entre os poderes, à custa de recurso público, muitas vezes oriundo exatamente destes cortes. Esta reflexão vai ao encontro do que Stuckler elabora em sua obra: austeridade para quem?

É preciso, ao final e ao cabo, compreender que o financiamento em saúde (à exceção daquele comprometido com o conflito de interesses da indústria e do capital, de uma forma geral) é realizado pelo povo brasileiro. Neste sentido, o discurso de César Victora, um dos cientistas mais promissores do Brasil, proferido no mesmo Congresso Brasileiro de Epidemiologia, precisa ser reforçado: “Devemos ter esta lealdade com a população que financiou muitos estudos no país, e nesta época que a tentação de emigrar é muito grande, nós temos que resistir e continuar construindo a nossa Saúde Coletiva".

A economia desumana: porque mata a austeridade demonstra, de forma clara, que a saúde pública é fortemente comprometida com o contexto social, político e econômico que a cerca, não só como provocadora de mudanças, mas como vulnerável às ações realizadas por outros setores. É, portanto, uma obra provocativa à reflexão dos rumos que o Brasil toma neste momento de instabilidade, e é um convite à reflexão do papel que a academia, juntamente com os serviços de saúde e a sociedade civil ocupam e exercem no cenário adverso de desmonte voluntário da saúde pública no país.

\section{Referências}

STUCKLER, D.; REEVES, A.; LOOPSTRA, R.; KARANIKOLOS, M.; MCKEE, M. Austerity and health: the impact in the UK and Europe. European Journal of Public Health, vol. 27, suppl. 4, p. 18-21, oct. 2017.

GREER, S.L.; BEKKER, M.; LEEUW, E.; WISMAR, M.; HELDERMAN, J.K.; RIBEIRO, S.; STUCKLER, D. HYPERLINK. Policy, politics and public health. European Journal of Public Health, vol. 27, suppl. 4, p. 40-43, oct. 2017.

\section{(cc) BY}

Este é um artigo publicado em acesso aberto sob uma licença Creative Commons. 